\title{
KOMBINASI TERAPI WARNA HIJAU, AROMATERAPI LAVENDER, DAN MUSIK UNTUK MENURUNKAN NYERI DAN KECEMASAN PERSALINAN
}

\section{THE COMBINATION OF GREEN COLOR, LAVENDER, AND MUSIC THERAPIES TO REDUCE LABOR PAIN AND ANXIETY}

\author{
Ari Andriyani $^{1 *}$, Mahindria Vici Virahaju ${ }^{2}$ \\ ${ }^{* 1}$ Prodi Kebidanan Stikes AKBIDYO, Jalan Parangtritis Km. 06 Sewon Bantul, D.I. Yogyakarta \\ email: rayoung.gayuh@gmail.com, Indonesia \\ ${ }^{2}$ Prodi Kebidanan Stikes AKBIDYO, Jalan Parangtritis Km. 06 Sewon Bantul, D.I. Yogyakarta \\ email: ind.vici@yahoo.com, Indonesia
}

\begin{abstract}
Background: The ideal application of holistic midwifery care is by paying attention to the psycho-neuroendocrino-immuno aspect.Midwives are expected to be able to facilitate mothers to get a natural, safe, comfortable, calm and pain free maternity experience. Combination of green color, lavender aromatherapy and music have not been utilized as many as other non-pharmacological therapies to reduce maternal pain and anxiety.

Objective: To determine the effectiveness of the combination of green color, lavender aromatherapy and music to reduce maternal pain and anxiety.

Methods: A quasy-experimental study with pre-test and post-test control group design was applied. Sixty mothers giving birth were divided intocontrol and experimental group., The combination of green color therapy, lavender aromatherapy and therapeutic music were delivered to experimental group whilst control group got normal standard care. Pain and anxiety were measured before and after treatment and then analized by using statistical methods.

Results: there was a significant difference between the level of pain in the treatment group and the control group $(p=0,0009)$ but there was no significant difference in the level of anxiety $(p=0,313)$.

Conclusion:The combination of therapiesare more effective in reducing pain in maternity as compared to conventional method.
\end{abstract}

Keywords: Green Color Therapy, labor pain, lavender aromatherapy, maternal anxiety, music therapy.

\section{PENDAHULUAN}

$\begin{array}{lrrr} & \text { Kehamilan dan } & \text { persalinan adalah } \\ \text { fungsi } & \text { tertinggi } & \text { dari } & \text { fisik } \\ \text { perempuan,pengalaman } & & \text { mendalam, }\end{array}$

membawa suatu arti yang bermakna untuk wanita tersebut, keluarga, dan komunitasnya, yang pada dasarnya adalah suatu pencapaian spiritual. Lahirnya anak merupakan perwujudan paling sempurna dari cinta manusia. Setiap wanita merupakan pribadi yang mempunyai hak, kebutuhan, dan harapannya sendiri, oleh karena itu dia harus berpartisipasi aktif dalam asuhannya selama kehamilan, persalinan, dan masa nifas, serta membuat pilihan dan keputusan tentang asuhan yang diberikan.

Kehamilan, persalinan, dan nifas merupakan fungsi fisiologis meskipun komplikasi kehamilan secara nasional dialami oleh $6,5 \%$ lbu hamil yang mengancam kesejahteraan ibu dan janin. ${ }^{1}$ Komponen penting dalam proses persalinan adalah jalan lahir, passenger (fetus dan plasenta), kekuatan kontraksi, dan respon psikologis. ${ }^{2}$ Akibat malfungsi salah satu faktor tersebut adalah waktu persalinan lebih lama, lebih nyeri, atau 
berakhir dengan bedah sesar.

Penerapan ilmu kesehatan secara holistik dengan memperhatikan aspek psycho neuro endocrino imuno (PNEI) bertujuan menyelaraskan jiwa dan pikiran sehingga menghindari gangguan keseimbangan saraf, hormon, dan daya tahan tubuh. Saat ini asuhan persalinan telah berkembang termasuk dalam halmengurangi rasa rasa cemas yang menegangkan, yang bertujuan memberi rasa nyaman, aman, dan menyenangkan. ${ }^{3}$ Seperti yang terjadi di Puskesmas Rawat Inap kota Yogyakarta dimana 86,8\% ibu hamil mengalami kecemasan sedang, sedangkan 13,2\% mengalami kecemasan rendah. Ibu hamil yang merasa takut, merasa sakit saat melahirkan, takut persalinannya berjalan tidak normal, takut dilakukan operasi, takut saat mengejan, takut disuntik, dan takut dijahit. ${ }^{4}$

Nyeri persalinan merupakan masalah yang harus dikelola dalam persalinan, sebanyak $90 \%$ wanita mengalami nyeri saat bersalin. ${ }^{5}$ Ibu bersalin mengharapkan dapat bersalin dengan normal dan lancar. Nyeri persalinan menyebabkan tingginya operasi sesar, salah satu penyebabnya karena para ibu lebih memilih persalinan yang relatif tidak nyeri. ${ }^{2,5}$

Persalinan sering digambarkan sebagai salah satu penyebab rasa nyeri yang paling kuat yang pernah dialami seorang ibu bersalin. ${ }^{2}$ Rasa takut dan cemas yang dialami ibu berkaitan dengan semakin besarnya rasa sakit yang dialami. Rasa takut menyebabkan ketegangan pada tubuh terutama pada rahim. Kondisi ini dapat menghambat proses persalinan alami, persalinan lebih lama, dan menimbulkan nyeri yang hebat. ${ }^{5}$ Nyeri persalinan memiliki sifat yang unik, merupakan kondisi yang fiologis, dan bukan merupakan respons dari suatu keadaan patologis. Nyeri yang timbul merupakan sinyal bahwa proses persalinan telah berlansung. ${ }^{6}$

Bidan diharapkan dapat memfasilitasi ibu untuk mendapatkan pengalaman bersalin yang alami, aman, nyaman, tenang, dan bebas akan nyeri. Sayangnya belum semua bidan menerapkan beberapa metode alamiah yang dapat membantu meredakan rasa nyeri.

Kombinasi terapi warna hijau, aromaterapi lavender dan musik dapat diberikan dalam waktu bersamaan pada ibu bersalin untuk memberikan kenyamanan dan pengalaman positif saat persalinan. Musik adalah bentuk seni paling subtil namun berpengaruh besar terhadap pusat fisik dan dan sistem saraf parasimpatetis. Cahaya dari panjang gelombang warna hijau mempunyai karakteristik menyeimbangkan serta daya penyembuhan. ${ }^{7}$

Metode non farmakologis yang belum diterapkan pada asuhan ibu bersalin adalah kombinasi terapi warna hijau, aromaterapi lavender, dan musik terapi. Penelitian ini bertujuan untuk mengetahui efektifitas kombinasi terapi warna hijau, aromaterapi 
lavender, dan musik terapi untuk menurunkan nyeri dan kecemasan ibu bersalin.

\section{BAHAN DAN CARA PENELITIAN}

Penelitian ini merupakan eksperimen analitikal observasional dengan pendekatan quasi-experimental pretest and post-test control group design melalui simple random sampling dari consecutive sampling sebanyak 60 responden. Data primer didapatkan dengan mengukur nyeri serta kecemasan sebelum dan setelah perlakuan di Puskesmas Rawat Inap Kota Yogyakarta, Puskesmas Sewon 1, dan Praktik Mandiri Bidan Mugi Rahayu dari bulan Mei-September 2018.

Data diambil pada ibu bersalin saat persalinan kala I fase aktif dengan memberikan perlakuan kombinasi terapi warna hijau, aromaterapi lavender, dan musik terapi. Terapi warna hijau diberikan dengan desain ruang bersalin bernuansa warna hijau, aromaterapi lavender diberikan dengan memberikan minyak esensial lavender murni 5-8 tetes menggunakan diffuser elektrik dengan jarak $30-60 \mathrm{~cm}$, serta musik terapi karya Mozart menggunakan speaker aktif. Sebelum mendapatkan perlakuan pre test dilakukan di ruangan yang berbeda kemudian dilanjutkan dengan pemberian inhalasi aromaterapi lavenver, dan musik terapi di ruang bersalin. Jarak waktu pre-test dan post-test minimal selama 30 menit. Pada kelompok kontrol pre tes dan post test dilakukan di ruang bersalin konvensional. Tingkat kecemasan saat pre test dan post test diukur menggunakan state-trait anxiety inventory (STALY1). ${ }^{8}$ Skor nyeri saat pretest dan post-test diukur menggunakan numeric rating scale (NRS). ${ }^{9}$

$$
\text { Hasil uji normalitas data }
$$
menggunakan uji kolmogorov-smirnov, uji statistik pre-test dan post-test pada kedua kelompok menggunakan uji paired sample $t$ test, untuk menganalisis perbedaan skor kecemasan kada kedua kelompokmenggunakan uji independent sample t-test dengan interval kepercayaan 95\% untuk mengetahui besarnya pengaruh metode kombinasi terapi warna hijau, aromaterapi lavender, dan musik terapi terhadap tingkat kecemasan dan nyeri ibu bersalin.

\section{HASIL DAN PEMBAHASAN}

Berdasarkan penelitian didapatkan hasil sebagai berikut:

Tabel 1 Karakteristik umum objek penelitian pada kedua kelompok

\begin{tabular}{|c|c|c|c|c|}
\hline \multirow{3}{*}{ Karakteristik } & \multicolumn{4}{|c|}{ Kelompok } \\
\hline & \multicolumn{2}{|c|}{ Perlakuan } & \multicolumn{2}{|c|}{ Kontrol } \\
\hline & $(n=30)$ & $\%$ & $(n=30)$ & $\%$ \\
\hline \multicolumn{5}{|l|}{ Usia } \\
\hline $20-25$ & 14 & 46.66 & 17 & 56.66 \\
\hline$>25-30$ & 10 & 33.33 & 8 & 26.66 \\
\hline$>30-35$ & 6 & 20 & 5 & 16.66 \\
\hline \multicolumn{5}{|l|}{ Pendidikan } \\
\hline SLTA & 24 & 80 & 23 & 26.66 \\
\hline Perguruan Tinggi & 6 & 20 & 7 & 16.66 \\
\hline
\end{tabular}

Tabel 1 di atas menunjukkan bahwa sebagian besar objek berusia 20-25 tahun 
dengan tingkat pendidikan sebagian besar SLTA. Tidak terdapat perbedaan pada usia dan tingkat pendidikan objek pada dua kelompok (comparable). Hal ini menunjukkan bahwa karakteristik responden bukan sebagai variabel perancu terhadap kecemasan dan nyeri ibu bersalin.

\section{Tabel 2 Hasil uji paired sample t-test tingkat Kecemasan dan nyeri lbu bersalin pada} kelompok perlakuan

\begin{tabular}{cccccc}
\hline Variabel & mean & $\mathbf{n}$ & $\mathbf{t}$ & $\mathbf{D f}$ & $\mathbf{p}$ \\
\hline Kecemasan &,- 200 & 30 & $-1,989$ & 29 &, 056 \\
$\quad$ Nyeri &,- 500 & 30 & $-4,349$ & 29 &, 000 \\
\hline
\end{tabular}

Sumber: data primer 2018

$$
\text { Dari tabel di atas diketahui }
$$

bahwatidak ada perbedaan bermakna secara statistik untuk kecemasan responden antara sebelum dan sesudah diberikan perlakuan, akan tetapi perbedaan yang bermakna dapat dilihat pada variabel nyeri.

\section{Tabel 3 Hasil uji paired sample t-test tingkat kecemasan dan nyeri lbu bersalin pada kelompok kontrol}

\begin{tabular}{cccccc}
\hline Variabel & mean & $\mathbf{n}$ & $\mathbf{t}$ & $\mathbf{D f}$ & $\mathbf{p}$ \\
\hline Kecemasan & $-5,200$ & 30 & $-3,236$ & 29 &, 003 \\
Nyeri & $-1,900$ & 30 & $-4,506$ & 29 &, 000 \\
\hline
\end{tabular}

Sumber: data primer 2018

Berdasarkan tabel di atas diketahui bahwa terdapat perbedaan rata-rata kecemasan dan nyeri responden pada kelompok kontrol antara pengambilan data pertama dan ke-2 yang signifikan secara statistik.

Berdasarkan uji independent sample t test dapat dilihat bahwa tidak ada perbedaan secara signifikan antara tingkat kecemasan kelompok kontrol dan perlakuan. Jika dilihat dari nilai mean pada kelompok perlakuan dan kelompok kontrol terdapat perbedaan mean kelompok perlakuan 44,80 dan mean kelompok kontrol 42,23 yang artinya nilai kecemasan responden pada kelompok kontrol lebih tinggi dibanding dengan kecemasan pada kelompok perlakuan.

Tabel 4 Perbandingan post-test kecemasan kelompok kontrol dan kelompokperlakuan

\begin{tabular}{ccccc}
\hline $\begin{array}{c}\text { Variabel } \\
\text { kecemasan }\end{array}$ & Mean & $\begin{array}{c}\text { Std } \\
\text { deviation }\end{array}$ & $\begin{array}{c}\text { Std } \\
\text { Error } \\
\text { mean }\end{array}$ & p \\
\hline Perlakuan & 44,80 & 9,911 & 1,810 & \\
kontrol & 42,23 & 9,616 & 1,756 &, 313 \\
\hline
\end{tabular}

Tabel 5 Perbandinganpost test nyeri kelompok kontrol dan kelompok perlakuan

\begin{tabular}{ccccc}
\hline $\begin{array}{c}\text { Variabel } \\
\text { Nyeri }\end{array}$ & Mean & $\begin{array}{c}\text { Std } \\
\text { deviation }\end{array}$ & $\begin{array}{c}\text { Std } \\
\text { Error } \\
\text { mean }\end{array}$ & p \\
\hline Perlakukan & 4,87 & 1,224 &, 224 &, 000 \\
kontrol & 7,03 & 1,884 &, 344 & \\
\hline
\end{tabular}

Berdasarkan uji independent sample $\mathrm{t}$ test di peroleh informasi bahwa terdapat perbedaan secara signifikansi antara tingkat nyeri kelompok kontrol dengan perlakuan.

Secara umum, objek penelitian berusia 20-35 tahun, dan tingkat pendidikan objek adalah sekolah menengah. Hasil analisis karakteristik umum objek penelitian usia, dan pendidikan pada kedua kelompok ditemukan tidak ada perbedaan yang bermakna. Dengan demikian, kedua kelompok layak untuk diperbandingkan. Perbedaan yang tidak bermakna untuk usia objek pada kedua kelompok memungkinkan adanya kesamaan kematangan emosional, 
pengalaman, dan informasi yang dimiliki oleh objek.

Berdasarkan uji independent sample $t$ testdisimpulkan terdapat perbedaan secara signifikansi antara tingkat nyeri kelompok kontrol dengan perlakuan. Hasil penelitian ini sejalan dengan penelitian sebelumnyayang melaporkan bawa setelah penghirupan aroma terapi lavender nyeri pada ibu bersalin turun secara bermakna. ${ }^{5,11,12}$

Hasil rata-rata skala nyeri pada kelompok intervensi setelah perlakuan kombinasi terapi warna hijau, aromaterapi lavender, dan musik terapi 4,87 (nyeri ringan) sedangkan pada kelompok kontrol 7.03 (nyeri hebat). Hasil tersebut tidak jauh berbeda dengan yang studi sebelumnya yang meliputi nyeri sedang $20 / 30$ dan nyeri berat $10 / 30$ orang . Setelah penghirupan aromaterapi lavender, skor nyeri persalinan berkurang, yaitu: sebelum perlakuan rata-rata 7,3 (SD 1,1) dan 5,9 (SD 1,4) sesudah perlakuan, derajat nyeri rata-rata persalinan kala I fase aktif dengan pengukuran NRS berupa nyeri ringansampai hebat. $^{5}$

Lavender merupakan salah satu minyak esensial analgesik yang mengandung 8\% terpena dan $6 \%$ keton. $^{12}$ Monoterpena merupakan jenis senyawa terpena yang paling sering ditemukan dalam minyak atsiri tanaman. Pada aplikasi medis monoterpena digunakan sebagai sedatif. Minyak lavender juga mengandung $30-50 \%$ linalil asetat. $^{13}$ Linalil asetat merupakan senyawa ester yang terbentuk melalui penggabungan asam organik dengan alkohol. Ester sangat berguna untuk menormalkan keadaan emosi serta keadaan tubuh yang tidak seimbang, dan juga memiliki khasiat sebagai penenang serta tonikum, khususnya pada sistem saraf. ${ }^{12}$

Linalil dan linalol yang dihirup masuk ke hidung ditangkap oleh bulbus olfactory kemudian melalui traktus olfaktorius yang bercabang menjadi dua, yaitu sisi lateral dan medial. Pada sisi lateral, traktus ini bersinap pada neuron ketiga di amigdala, girus semilunaris, dan girus ambiens yang merupakan bagian dari limbik. Jalur sisi medial juga berakhir pada sistem limbik. Limbik sebagai tempat pusat memori, suasana hati, dan intelektualitas. ${ }^{14}$

Bagian dari limbik yaitu amigdala bertanggung jawab atas respon emosi kita terhadap aroma. Hipocampus bertanggung jawab atas memori dan pengenalan terhadap bau juga tempat bahan kimia pada aromaterapi merangsang gudanggudang penyimpanan memori otak kita terhadap pengenalan berbagai aroma.Aroma yang menyenangkan akan menciptakan perasaan tenang dan senang sehingga dapat mengurangi kecemasan. Aromaterapi menstimulasi pengeluaran enkefalin atau endorfin pada kelenjar hipothalamus, PAG, dan medula rostral ventromedial. Enkefalin merangsang daerah di otak yang disebut raphe nucleus untuk menyekresi serotonin sehingga 
menimbulkan efek rileks, tenang, dan menurunkan kecemasan. ${ }^{15}$

Serotonin juga bekerja sebagai neuromodulator untuk menghambat informasi nosiseptif dalam medula spinalis. Neuromodulator ini menutup mekanisme pertahanan dengan cara menempati reseptor di kornu dorsalis sehingga menghambat pelepasan substansi $P$, sehingga impuls nyeri tidak dapat melalui neuron proyeksi dan tidak dapat diteruskan pada proses yang lebih tinggi di kortek somatosensoris dan transisional. ${ }^{16}$

Hasil penelitian ini juga sejalan dengan penelitian sebelumnya tentang terapi warna hijau yang melaporkan bahawa terapi tersebut secara signifikan menurunkan kecemasan, kecemasan ibu hamil, tingat stres lansia. tekanan darah sistolik pada lanjut usia.

Hasil penelitian ini juga didukung olehShealy dkk (1996) dalam Honig (2007), yang mengukur perubahan dalam berbagai zat kimia saraf dan neurohormonnya sebagai respon terhadap cahaya berwarna. Warna hijau meningkatan kadar serotonin hingga $104 \%$, oksitosin hingga $45,5 \%$, dan beta endorfin hingga 33\%. Warna hijau juga menyebabkan terjadinya penurunan kadar norepinefrin hingga $29 \%{ }^{17}$

Warna hijau dengan panjang gelombang 490-560 nm berefek pada sistem saraf secara keseluruhan, terutama bermanfaat bagi sistem saraf pusat. Vernolia, 1988 dalam Edge menyatakan warna hijau memiliki efek penenang, mengurangi iritasi dan kelelahan, serta dapat menenangkan gangguan emosi dan sakit kepala. ${ }^{18}$

Retina merupakan reseptor permukaan untuk informasi visual, retina merupakan bagian dari otak meskipun secara fisik terletak di perifer dari sistem saraf pusat (SSP). Komponen yang paling utama dari retina adalah sel-sel reseptor sensoris atau fotoreseptor dan beberapa jenis neuron dari jaras penglihatan. Lapisan terdalam (neuron pertama) retina mengandung fotoreseptor (sel batang dan sel kerucut) dan dua lapisan yang lebih superfisia mengandung neuron bipolar (lapisan neuron kedua) serta sel-sel ganglion (lapisan neuron ketiga). Semua cahaya yang masuk ke mata direduksi menjadi 3 komponen RBG (Red, Green,Blue) selanjutnya ketiga warna dikirim ke otak melalui 3 chanel yaitu red-green channel, blue-yellow channel, dan black-white channel. ${ }^{17}$

Transmisi warna menuju sistem limbik melalui retinohypothalamic track yang menghubungkan sistem saraf dengan Autonomic Nervus Sistem (ANS) menuju ke sistem endokrin yang kemudian menstimulasi pengeluaran hormon serotonin dan endorfin yang mengubah mood seseorang menjadi rileks dan ketegangan otot menurun. ${ }^{17}$

Salah satu jalur utama dari mekanisme transmisi warna menuju system limbik dan sistem endokrin adalah 
Retinohypothalamic tract, di mana hipotalamus menghubungkan sistem saraf dengan Autinomic Nervous System (ANS) dan sistem endokrin. ${ }^{17}$

Terapi warna hijau akan merangsang pelepasan serotonin yang mampu mengaktifkan reseptor serotonin presinaps maupun postsinaps kemudian terjadi peningkatan kadar serotonin dalam tubuh yang akan meningkatkan mood seseorang sehingga dapat menciptakan rasa bahagia dan menurunkan stres. ${ }^{18}$

Salah satu peran penting serotonin dalam kondisi normal adalah mengatur status mood dan serotonin merupakan hormon yang menenangkan diri yang dapat membuat seseorang merasa senang. Adapun hormon lain yang dirangsang oleh hipotalamus adalah oksitosin. Oksitosin dapat menginduksi anti stress serta memberikan efek dalam penurunan tekanan darah dan kadar kortisol. ${ }^{19}$ Tingkat oksitosin berhubungan dengan kecemasan dan stres secara dua arah, yaitu oksitosin memberikan efek ansiolitik dan juga dirilis dalam respon terhadap stres. Pemberian terapi warna hijau dapat meningkatkan kadar oksitosin dalam darah, sehingga efek ansiolitik yang dikeluarkan dapat menurunkan kecemasan. ${ }^{19}$

Berdasarkan studi metaanalisis, musik dapat digunakan sebagai pilihan pendekatan dalam membantu individu yang mengalami hambatan kondisi fisik, prilaku, dan psikologis agar menjadi lebih baik. ${ }^{20}$ Dalam kebidanan, jenis musik yang lambat dan tenang dapat digunakan sebagai penenang untuk mempromosikan relaksasi selama persalinan kala I. Di Austin, Texas, program musik digunakan selama kehamilan trimester ketiga kehamilan. Seperti yang dilaporkan Tournaire, calon ibu dan pasangannya diizinkan untuk memilih jenis musik yang mereka sukai untuk berbagai tahap persalinan. Setelah melakukan penelitian terhadap 30 ibu bersalin, hanya separuh dari wanita yang mendengarkan musik membutuhkan analgesia. ${ }^{21}$

Studi yang dilakukan secara acak,Durham dan Collins tidak dapat menunjukkan nilai musik dalam mengurangi kebutuhan akan analgesik. Tetapi perasaan objektif kepuasan dilaporkan lebih tinggi dalam kelompok yang mendengarkan musik. Dalam uji coba terkontrol secara acak oleh Phumdoung dan Good, 110 wanita primipara, selama fase aktif persalinan, diberi perlakuandalam grup musik lembut selama 3 jam $(n=55)$ atau kelompok kontrol $(n=55)$. Dual VAS digunakan untuk mengukur sensasi nyeri sebelum perlakuan dan setiap tiga jam. Hasilnya menunjukkan bahwa ibu bersalin pada kelompok musiksensasi nyeri yang jauh lebih sedikit $(P$ $<0,001)^{21}$

Hasil penelitian serupa yang dilaporkan oleh Liu bahwa kelompok eksperimen memiliki rasa sakit, kecemasan, dan suhu jari yang lebih rendah secara signifikan selama fase laten persalinan. Namun, tidak 
ada perbedaan signifikan yang ditemukan antara kedua kelompok pada semua ukuran hasil selama fase aktif. ${ }^{22}$

$$
\text { Hasil review oleh Setyawan }
$$

menunjukkan bahwa $76 \%$ perawatan standar ruangan secara konvensional yang dikombinasikan dengan terapi musik lebih efektif menurunkan tingkat kecemasan dan $76,2 \%$ efektif menurunkan tingkat nyeri pada pasien dibandingkan terapi konvensional saja. Tujuh puluh lima persen perawatan konvensional yang dikombinasikan dengan terapi suara alam lebih efektif menurunkan kecemasan dan efektif menurunkan tingkat nyeri pasien dibandingkan dengan terapi konvensional. Perawatan konvensional yang dikombinasikan dengan terapi musik relaksasi dan suara alam menunjukkan lebih efektif menurunkan nyeri dan kecemasan pasien. $^{23}$

Bartlett melaporkan seperti yang dikutip dalam Halim bahwa mendengarkan musik klasik selama 15 menit terbukti dapat meningkatkan tingkat Interleukin-1 (IL-1) dalam darah dari $12,5 \%$ menjadi $14 \%$, hal tersebut menunjukkan indikator peningkatan imunitas. Selain itu, para ilmuwan menyimpulkan bahwa musik tersebut dapat menyebabkan pengalaman emosional yang mendalam dan positif yang melepaskan hormon yang berkontribusi untuk mengurangi faktor-faktor yang menyebabkan penyakit. Detak jantung dan respirasi merespons berbagai variabel musik seperti frekuensi, tempo, volume, dan beat. ${ }^{24}$

Mengacu teori gate control mekanisme musik dalam proses menurunkan rasa nyeri di mana impuls musik yang berkompetisi mencapai korteks serebri bersamaan dengan impuls nyeri, akan berefek pada distraksi kognitif dalam inhibisi persepsi nyeri. Ketika musik yang mempunyai efek terapi diperdengarkan, midbrain meningkatkan pengeluaran beta endorphin hormone dan Gamma Amino Butyric Acid (GABA) yang dapat mengeliminasi neurotransmitter rasa nyeri pada pusat persepsi dan interpretasi sensorik somatik di otak sehingga efeknya nyeri berkurang. ${ }^{16}$

Berdasarkan uji analisis tidak ada perbedaan secara signifikan antara tingkat kecemasan kelompok kontrol dengan perlakuan. Namun jika dilihat dari nilai mean pada kelompok perlakuan dan kelompok kontrol perbedaan mean kelompok perlakuan 44,80 dan mean kelompok kontrol 42,23 yang artinya nilai kecemasan responden pada kelompok kontrol lebih tinggi dibanding dengan kecemasan pada kelompok perlakuan. Hal tersebut dimungkinkan karena perbedaan dari cara intervensi, pada penelitian sebelumnya oleh Tournaire intervensi diberikan sejak ibu masih hamil sedangkan pada penelitian ini dilakukan pada saat ibu bersalin kala I fase aktif. ${ }^{21}$

Kecemasan atau takut menghadapi persalinan menimbulkan ketegangan vegetatif otot-otot polos dan pembuluh darah. 
Hal ini dapat menyebabkan kekakuan serviks dan hipoksia pada uterus yang menyebabkan impuls nyeri bertambah banyak. Perasaan sakit dan impuls sakit melalui sistem thalamolimbik ke korteks serebri, menambah perasaan takut dan kemudian kembali lagi ke lingkaran setan lagi yang disebut sebagai sindroma takut-tegang-nyeri yang dikenal juga sebagai Tense mind-Tense cervixTenselabour. $^{25}$

\section{Penerapan terapi komplementer} aromaterapi, terapi warna hijau, dan musik terapi untuk menurunkan kecemasan dan nyeri pada ibu bersalin sebenarnya mudah diterapkan untuk melengkapi asuhan konvensional serta memutuskan siklus takuttegang-nyeri sesuai dalam konsep psychoneuro-endocrino-imuno.

Asuhan komplementer terutama perpaduan kombinasi terapi warna hijau, aromaterapi, dan musik terapi sebenarnya sudah menjadi bagian asuhan persalinan terutama di Puskesmas rawat inap namun belum optimal, di antaranya sudah tersedia tape recorder untuk membantu terapi musik, namun penggunaannya juga belum optimal karena komitmen dari penolong persalinan serta dinilai kurang praktis.

Terapi warna hijau sudah diberikan meskipun belum optimal di antaranya pada ruang bersalin sudah dengan dinding berwarna hijau namun desain interiornya sepertinya belum memperhatikan aspek keindahan. Penggunaan aromaterapi untuk melengkapi asuhan konvensional belum diterapkan karena jika idealnya penggunaanya menggunakan diffuser dan minyak esensial murni belum tersedia anggaran di era BPJS.

Faktor psikososial berpengaruh pada persepsi nyeri ibu dan kemampuan untuk mengatasinya: Nyeri persalinan bersifat sangat subjektif, hal ini dikarenakan manusia adalah pribadi yang unik, setiap ibu bersalin mengamati, mengalami, dan menanggapi rasa nyeri dengan caranya masing-masing. Ketika ibu mengalami stres, takut atau terkejut, akan memicu kerja sistem simpatis dan parasimpatis. ${ }^{26}$

Kecemasan ibu bersalin yang berlebihanmeningkatkan kadar katekolamin dalam darah yang berakibat meningkatnya aliran darah menuju pelvik dan peningkatan ketegangan pada otot.Tubuh meresponsnya dengan penyempitan dan menghambat aliran darah serta oksigen sehingga berdampak pada kerja otot rahim, hal ini menimbulkan nyeri hebat yang dirasakan oleh ibu bersalin saat kontraksi. ${ }^{26}$

Bebas dari perasaan takut dapat memperlancar persalinan, baik dalam kala I maupun kala II. Jika rasa takut tidak ada, maka rasa nyeri juga tidak ada. Rasa takut menyebabkan pembuluh-pembuluh arteri yang mengarah ke rahim berkontraksi dan menegang, hingga akhirnya menimbulkan nyeri. Tanpa adanya rasa takut, otot-otot rileks dan lentur, serviks menipis serta membuka saat terjadi kontraksi. 
Jika ibu bersalin mampu mengatasi rasa cemas, maka ibu dapat menjalani persalinan dengan rileks dan tenang. Kombinasi terapi warna hijau, aromaterapi, dan musik terapi menjadi bagian mindbodyintervention, yang berguna untuk memutuskan siklus kecemasan dan adanya usaha untuk mengatasi kecemasan. ${ }^{27}$

\section{Proses perseptual dan kognitif yang} kompleks dalam sistem saraf pusat berpengaruh terhadap impuls nyeri sensoris perifer serta sinyal emosional dan sinyal kognitif pada korteks afeksi dan kognisi akan berintegrasi dan menimbulkan persepsi yang diterima sebagai pengalaman nyeri. Secara sederhana persepsi dapat didefinisikan sebagai berikut: persepsi adalah hasil integrasi dari apa yang ada pada pusat kognisi, pusat afeksi, dan sistem sensoris diskriminatif yang dirasakan oleh individu, serta bagaimana cara individu tersebut menghadapinya, dengan fight atau flight. ${ }^{28}$

\section{KESIMPULAN}

Berdasarkan hasil penelitian maka dapat disimpulkan Terapi warna hijau, aromaterapi lavender dan musik terapilebih efektif menurunkannyeri pada ibu bersalin dibandingkan dengan metode konvesional, namun tidak ada perbedaan pada tingkat kecemasan pada kedua kelompok perlakuan.

Berdasarkan penelitian ini dapat dikembangkan penelitian lebih lanjut untuk membandingkan kombinasi terapi warna hijau, aromaterapi lavender, dan musik terapi dengan metode mind-body intervention yang lain sebagai metode manajemen takuttegang-nyeri, dan pengaruhnya pada lama durasi persalinan, kadar hormon stres, outcome persalinan dan bayi, perkembangan anak, kepuasan ibu dan suami, serta penolong persalinan.

Diharapkan terapi warna hijau, aromaterapi lavender, dan musik terapi dapat diterapkan pada pelayanan asuhan persalinan di Puskeskemas Rawat Inap serta Bidan Praktik Mandiri sebagai asuhan komplementer yang melengkapi asuhan konvensional.

\section{TERIMA KASIH}

1. Direktorat Riset dan Pengabdian Masyarakat DRPM Kemenristekdikti yang telah mendanai penelitian PDP ini.

2. Musinggih Djarot Roujani, dr, Sp.KJ, selaku Ketua Sekolah Tinggi IImu Kesehatan Akbidyo.

\section{KEPUSTAKAAN}

1. Badan Penelitian dan Pengembangan Kesehatan Kementrian Kesehatan Repoblik Indonesia. Riset Kesehatan Dasar 2010 [Internet]. Jakarta; 2010. Available from: http://www.riskesdas.litbang.depkes.go.id/ download/TabelRiskesdas2010. Pdf

2. Cunningham F, Donald PM GN. Williams Obstetrics. 21st ed. The Mc Graw $\neg$ Hill Companies Inc; 2006.

3. Putra ST AE. Psikoneuimunologi Kedokteran. 1st ed. Surabaya: Gramik; 2005.

4. Andriyani.A. Pengaruh Kelas Hypnobirthing Terhadap Kecemasan lbu Hamil Di Puskesmas Rawat Inap Kota 
Yogyakarta. UNPAD; 2013.

5. Tarsikah, Susanto H SH. Penurunan Nyeri Persalinan Primigravida Labor Pain Reduction in Primigravida Active Phase after Inhalation of Lavender Aromatherapy. MKB. 2009;44(1):19-25.

6. Nuraini TA. Konstruksi alat ukur kecemasan pada wanita hamil. 2006;64.

7. Bassano $\mathrm{M}$ et al. Terapi Musik dan Warna. Yogyakarta: Araska; 2015

8. Spielberger. Anxiety curent trends in thoery and research. New York and London: Academic press; 1972.

9. Board CMEA. Pathophysiology of Pain and Pain Assessment Module 1 Pain Management: Pathophysiology of Pain and Pain Assessment American Academy of Orthopaedic Surgeons American College of Surgeons. Pain. 2009;0(December):1-12.

10.Karo $H$ et al. Lavender (lavandula angustifolia) Aromatherapy as an alternative treatment in reducing pain in primiparous mothers in the active first stage of labor. Belitung Nurs J. 2017;3(4):420-5.

11.Karlina S, Reksohusodo S, Widayati A. The Influence of Lavender Aromatherapy Inhalation to Relieve Physiological Labor Pain Intensity i n Primipara Inpartu Active Phase in BPM "Fetty Fathiyah" Mataram City. Fak Kedokt Univ Brawijaya. 2014;108-19.

12.Price S PL. Aromatherapy for health professionals. 2nd ed. London: Churchil Living Stone; 2003.

13.Wiryodidagdo S. Kimia dan farmakologi bahan alami. 2nd ed. Jakarta: EGC; 2008.

14. Hutasoit A. Panduan Praktis Aromaterapi untuk Pemula. Jakarta: Gramedia Pustaka Utama; 2002.

15.Baehr M. Diagnosis Topik Neurologi DUUS. Jakarta: EGC; 2010.

16.Guyton and Hall. Buku Ajar Fisiologi Kedokteran. 11th ed. Jakarta: EGC; 2007.

17. Honig LM. Physiological And Psychological Response To Colored Light
[Internet]. Saybrook; 2007. Available from: http://gradworks.umi.com/3369590.pdf

18.Uvnäs-moberg K, Petersson $M$. Social Interaction, Growth and Healing. Diabetes [Internet]. 2005;51(1):1-25. Available from:

http://www.ncbi.nlm.nih.gov/entrez/query.f cgi? $\mathrm{cmd}=$ Retrieve $\& \mathrm{db}=$ PubMed $\&$ dopt $=$ Cit ation\&list_uids $=15834840$

19. Edge KJ. Wall Color of Patient's Room: Effect on Recovery [Internet]. University of Florida; 2003. Available from: http://etd.fcla.edu/UF/UFE000857/ed ge k.pdf

20.Dewi MP. Studi Metaanalisis: Musik Untuk Menurunkan Stres. J Psikol. 2009;36(2):106-15.

21.Tournaire $M$, Theau-Yonneau A. Complementary and Alternative Approaches to Pain Relief during Labor. Evidence-Based Complement Altern Med. 2007;4(4):409-17.

22.Liu YH, Chang MY, Chen $\mathrm{CH}$. Effects of music therapy on labour pain and anxiety in Taiwanese first-time mothers. J Clin Nurs. 2010;19(7-8):1065-72.

23.Setyawan D, Susilaningsih $F$ EE. Intervensi Terapi Musik Relaksasi dan Suara Alam (Nature Sound) Terhadap Tingkat Nyeri dan Kecemasan Pasien. J Keperawatan dan Kebidanan. 2013;1:448-62.

24. Halim S. Music as a complementary therapy in medical treatment. Med $\mathrm{J}$ Indones. 2013;250.

25.Downe S. Normal Chilbirth Evidance and Debate. London: Churchil livingstone; 2004.

26.Mander R. Nyeri Persalinan. Sugiharto B S, editor. Jakarta: EGC; 2004.

27.Beddoe AE, Lee KA. Mind-Body interventions during pregnancy. JOGNN $J$ Obstet Gynecol Neonatal Nurs. 2008;37(2):165-75.

28.Taylor S. Health Psychology. New York: McGraw-Hill; 2006. 